\title{
Innovation Research of the"Internet plus" Volleyball Teaching System in the Context of the Information Age
}

\author{
Yang Tian (D 0001160024@gdgm.edu.cn ) \\ Guangdong Polytechnic of Industry and Commerce
}

Research

Keywords: Internet Information, Internet Plus, Volleyball, Volleyball Teaching, Course Scheduling Model

Posted Date: November 12th, 2020

DOl: https://doi.org/10.21203/rs.3.rs-104008/v1

License: (c) (i) This work is licensed under a Creative Commons Attribution 4.0 International License.

Read Full License 


\title{
Innovation Research of the "Internet plus" Volleyball Teaching
}

\section{System in the Context of the Information Age}

\author{
Yang Tian ${ }^{1, \mathbf{a}^{*}}$ \\ ${ }^{I}$ Department of Physical Education and Arts, Guangdong Polytechnic of Industry and Commerce, \\ Tianhe 510510, Guangzhou, China \\ ${ }^{a}$ Email:0001160024@gdgm.edu.cn \\ *Corresponding author
}

\begin{abstract}
Due to the rapid development of internet technology, big data, artificial intelligence, multimedia and other new technologies are updated rapidly, and all walks of life have an increasingly urgent demand for information technology. As a base for teaching and cultivating talents, schools should adapt to the development of the times and make full use of information technology to carry out educational activities. For example, "Internet plus" can be used for innovation in school teaching mode. This paper mainly talks about the innovation research of "Internet plus" volleyball teaching system in the context of the information age. This paper analyzes the influence of "Internet plus" on the teaching mode in universities and colleges, and studies how to use the "Internet plus" to change the teaching mode of Volleyball in universities. The results of this paper show that the "Internet plus" volleyball teaching is a new teaching system that is united and common. It helps to break the traditional volleyball teaching mode in universities and colleges, and improve the single teaching form, the limitation of time and space, and so on. The confidence interval of SPSS17.0 is 0.96 . The use of multimedia in the "Internet plus" volleyball teaching system improves the volleyball performance of students, and promotes the smooth progress of Volleyball Teaching in Colleges and universities.
\end{abstract}

Keywords: Internet Information, Internet Plus, Volleyball, Volleyball Teaching, Course Scheduling Model

\section{Introduction}

Innovation-driven development strategies, industrial structure restructuring and upgrades are the mainstream. It changes the traditional industry's appearance and will change the traditional teaching mode. With the development of science and technology, the traditional teaching system of school has gradually transformed into modern information technology. Nowadays, colleges and universities in China generally have volleyball elective courses in the physical education curriculum arrangement. As far as volleyball teaching in colleges is concerned, volleyball sports technology is difficult and the change law is complex. If college physics teachers simply explain the theoretical knowledge of volleyball, students' understanding of the intrinsic value of volleyball may be biased. Only the combination of theoretical knowledge and practical proof can meet the teaching requirements of volleyball colleges and universities. For example, the change of volleyball tactics and the sense of position can not be described in theory, but must be completed with specific volleyball practice.

Deren Li argued that "'Internet plus"' represented a new social form and provided a broad platform for reform, innovation and development. Given the continued convergence of the Internet in various fields,"'Internet plus"' there are serious changes and impacts on various traditional industries. For example,"'Internet plus"'has set favorable conditions for transforming earth observation and satellite navigation into smart real-time geospatial information services. In order to realize continuous, 
all-weather, and all-terrain services, Deren Li had found the disadvantages that the existing volleyball education system has a finite cover, slow response speed, and poor operability. In addition, to meet the volleyball teaching service requirements in the field about big data, namely, "Internet plus volleyball teaching", we must establish a service system that is inherent of the school family network. For reference only, for the development of volleyball teaching system, this paper discussed three dimensions of structure and suggestions for "Internet plus volleyball teaching" service system. Finally, we recognize the needs of "Internet plus" volleyball teaching service system, examine the teaching and important supporting technologies. However, the cost of this research method is high [1]. Kim I. used a hybrid approach design, which included qualitative teaching data from a male physical education teacher and quantitative learning data from his 24 eighth graders. In the five days before and after the content knowledge seminar, two kinds of volleyball teaching classes (a total of $1 / 420$ classes) were observed, and each class was recorded and videotaped. Descriptive and continuous comparative analysis methods were used to analyze the data. The results show that after teaching content knowledge, teachers use more oral teaching methods, such as task progress, comprehensive skills practice, small games, content adaptation and so on. These changes in teaching methods ultimately affect students' classroom performance, participation and cognitive understanding of the content. The results show that there is a stable relationship among teachers, content and students' learning by showing that other elements also change when teachers' content knowledge level changes. Research on teaching related work can guide the development of teachers' professional work, so as to enrich the professional knowledge and professional level of teachers. This method has many processes and is not conducive to the study[2] .Dao SD has developed a new random volleyball course scheduling model for virtual course scheduling system, which is an uncertain scheduling model. Two subproblems, course selection and tutor selection, are completely combined to explore opportunities to improve the efficiency of course selection in the system. Dao SD first gives the explicit mathematical formula of the proposed model, then proposes an innovative method based on Monte Carlo simulation and optimization solver to finish the problem, and then the effectiveness of this model was verified through comprehensive case analysis. However, this research method is relatively complex, which is disadvantageous for dissemination in universities[3].

In the volleyball teaching system,"Internet plus" technology can be combined with various audio-visual forms to complete and achieve the teaching effect. Students can improve their understanding of volleyball by observing volleyball technology, physical exercise, sports competition and routine training and other related resources. This is conducive to improve the efficiency of volleyball teaching in colleges, and can mobilize the enthusiasm of students to learn volleyball.

This paper analyzes the beneficial effect of "Internet plus" on the way of teaching in universities and colleges in the information age. It is concluded that "Internet plus" volleyball contributes to the development of the volleyball teaching system in colleges and universities. The novelty of this paper is: (1) to analyze the application of "Internet plus" in the volleyball teaching system in colleges and universities; (2) to analyze the application of volleyball teaching and training facilities in universities; (3) to analyze the application of the network; (4) to analyze the application of the APP to the volleyball teaching system in colleges and universities.

\section{Innovative Research Methods of "Internet Plus" Volleyball Teaching System in the Context of} the Information Age 
"Internet plus" refers to the Internet in innovation 2 (information age, form of innovation in the knowledge society) and in the development and creation of a new form of economic and social development based on innovation 2, in the knowledge society. "Internet plus" is "Internet plus traditional industries". With the development of science and technology, the use of information technology and internet platform unifies the internet and traditional industries, and the advantages and characteristics of the internet create some new growth opportunities [4]."Internet plus" uses its own advantages to optimize and upgrade traditional industries so that traditional industries can adapt to its new growth [5]. The practice of internet thinking has promoted the continuous development of economic forms, thereby promoting the vitality of social economic entities, and providing a broad network platform for reform, innovation and growth. Add various traditional industries", but this is not a simple supplement. However, the internet and traditional industries are expanding with the use of information and communication technologies and internet platforms [6], which represents a new kind of society form, the internet is fully utilized in the field of optimizing and integrating the distribution of social resources, the deep integration of internet innovation achievements in the economic and social fields, and the improvement of the innovation ability and productivity of the entire society; taking the internet as the infrastructure and implementation tool, it forms a broader new mode of economic development [7].

The word "Internet + " is the core word, and it is the starting point of the "Internet plus" project [8]. The "Internet plus" project can be expressed from two levels. On the one hand, the word "Internet" and the symbol "+" in the term "Internet + " can be understood separately [9]. The sign "+" indicates the sign "addition", and indicates addition and union. Thus, the "Internet plus" project covers the traditional industries such as the internet, which is a new project for different industries. The implementation means is the combination and deep integration of internet and traditional industries [10]. On the other hand, the "Internet plus" is a whole, and its profound significance lies in the integration of in traditional industries through the internet [11]. The internet uses network functions such as openness and equal interaction of traditional industries, to change the production and industrial structure of traditional industries through analysis and integration to enhance the driving force of economic growth, thereby improving efficiency and promoting the rapid growth of the national economy[12].The process is shown in Figure 1:

\section{2 "Internet Plus" Volleyball Teaching Research Method}

(1) Literature retrieval

Through the internet data resource website, such as CNKI, Wanfang Data, Du Xiu, SpringerLink and so on, we searched a large number of documents and materials, classified, summarized and analyzed them, providing the first and basic theoretical support for the "Internet plus" volleyball teaching.

\section{( 2 ) Questionnaire survey}

The questionnaire survey is divided into two parts: before and after the implementation. The questionnaire before the implementation mainly raised questions from the aspects of student mobile terminal equipment holding, student exercise habits and network uploading and downloading [13].It was carried out after applying the questionnaire. The research results were mainly carried out from the systematic teaching results and volleyball "Internet plus" teaching methods, as well as students' satisfaction with the "Internet+" teaching methods[14]. 
At the end of the questionnaire survey, the reliability of the questionnaire was tested. For example, the questionnaire survey was conducted again after a few weeks. The statistical software SPSS17.0 was used to calculate the correlation coefficient before and after the basic situation and the satisfaction of students after class. The correlation coefficient was $\mathrm{r}=0.93, \mathrm{P}<0.01$. The reliability was high, the reliability of the questionnaire results was high, and the questionnaire results met the requirements $[15-16]$.

\section{( 3 ) Establishment of course scheduling model}

When dealing with the unilateral constraint volleyball course scheduling problem, if it is assumed that students' preference for volleyball course can be fully quantified, it will naturally associate with the auction model of market economy [17]. As an educational resource, volleyball lessons are auctioned to students through the education management system, and the degree of preference is reflected in the behavior of the students in the offer. Of course, the price in the auction process is virtual, and the initial capital of each student is basically the same, so as to ensure the fairness of the process [18]. Inspired by the competitive equilibrium from equal incomes (CEEI), Eric Budish proposed a dynamic clearing model in 2009 to solve the unilateral constrained course scheduling problem [19]. The traditional CEEI problem requires participants to have the same original capital and to clear their positions perfectly at the end of the auction [20]. Budish modified the condition of the problem, students no longer have the same initial capital, but there are subtle differences. In this case, the solution with small clearance error can be realized, and the fairness is guaranteed to a certain extent, and the algorithm efficiency is improved [21-22].

Input: students provide personal course preference function, write $\left(\hat{\mathrm{u}}_{\mathrm{i}}\right)_{\mathrm{i}=1}^{\mathrm{N}}$, and provide budget $\mathrm{b}_{\mathrm{i}}^{*}$ for each student $i, \quad b_{i}^{*}$ obey the uniform distribution of $[1,1+\beta]$, and satisfy $0<\beta \leq \min \left(\frac{1}{N}, \frac{1}{k-1}\right)$ [23]. Output: complete timetable ${ }^{*}$, clearance price $\mathrm{p}^{*}$ and clearance error $\alpha$. Calculate the clearance $\operatorname{price}\left(\mathrm{p}_{\mathrm{j}}\right)_{\mathrm{j}=1}^{\mathrm{M}}$, arrange the class schedule $\left(\mathrm{x}_{\mathrm{i}}\right)_{\mathrm{i}=1}^{\mathrm{N}}$, and calculate the student preference function, so as to achieve the most efficient under the condition of cost restriction [24].

$$
\forall \mathrm{i}: \mathrm{x}_{\mathrm{i}}=\arg \max _{\mathrm{x}^{1} \in \phi_{\mathrm{i}}}\left[\hat{\mathrm{u}}_{\mathrm{i}}\left(\mathrm{x}_{\mathrm{i}}\right): \sum_{\mathrm{j}} \mathrm{x}_{\mathrm{ij}} \mathrm{p}_{\mathrm{j}}^{*} \leq \mathrm{b}_{\mathrm{i}}^{*}\right]
$$

Calculation the minimum clearance error $\alpha$.

$$
\alpha=\sqrt{\sum_{j} \xi_{j}^{2}}
$$

When $\mathrm{p}_{\mathrm{j}}^{*}>0$.

$$
\xi_{\mathrm{j}}=\sum_{\mathrm{i}} \mathrm{x}_{\mathrm{ij}}^{*}-\mathrm{q}_{\mathrm{j}}
$$

$$
\text { When } \mathrm{p}_{\mathrm{j}}^{*}<0 \text {. }
$$

$$
\xi_{\mathrm{j}}=\max \left(\sum_{\mathrm{i}} \mathrm{x}_{\mathrm{ij}}^{*}-\mathrm{q}_{\mathrm{j}}, 0\right)
$$


The purpose of "Internet plus" volleyball teaching experiment is to apply the "Internet plus" technology teaching mode to the volleyball course, and verify the effectiveness of the teaching mode through experiments. Through the experimental intervention, volleyball "Internet plus" technology teaching mode is applied to volleyball teaching courses. The teaching effect of volleyball "Internet plus" technology teaching mode and traditional teaching mode on students' Volleyball theoretical knowledge learning, skill learning and learning interest is compared, and the learning situation of "Internet plus" volleyball technology teaching mode is also studied. Satisfaction analysis [25].

\subsection{Selection and Test of Experimental Indexes}

According to the final examination standard of volleyball course in colleges, and according to the advise of volleyball teachers, the test indexes of volleyball teaching experiment are determined. Before the experiment, the test indexes are special physical fitness index and skill test index. The physical fitness index includes height quality, run-up touch height and shot put, and the skill test index includes the technical evaluation and standard of volleyball practice. After the experiment, the test indexes are skill test index, volleyball theory achievement index and students' learning situation and satisfaction. Here is shown in Table 1:

Table 1.Experimental test items

\begin{tabular}{|c|c|c|}
\hline \multicolumn{2}{|c|}{ Before the experiment } & After the experiment \\
\hline \multirow{2}{*}{$\begin{array}{c}\text { Special physical } \\
\text { fitness index }\end{array}$} & Height & $\begin{array}{r}\text { Special physical fitness } \\
\text { index }\end{array}$ \\
\cline { 2 - 2 } & Run up to touch height & $\begin{array}{c}\text { Volleyball theoretical } \\
\text { achievements }\end{array}$ \\
\cline { 2 - 2 } & Shot put & Students' learning \\
& Skill test indicators & Volleyball technical \\
evaluation & situation and satisfaction \\
& $\begin{array}{r}\text { Volleyball up to standard } \\
\end{array}$ & \\
\hline
\end{tabular}

\subsection{Setting of Experimental Objects and Control Groups}

Through screening and eliminating the interference factors, the subjects of the experiment were selected as 30 students of volleyball special class and 30 students of physical education department of a certain university. The physical fitness of the two types of students was tested before the experiment. On the basis of the same number of students, the students are divided into two groups, the experimental group is volleyball students, and the other group is selected volleyball students. According to the group, the test space and time are the same.

At the same time, the volleyball experimental group and control group were tested on the special quality index. The data in the table are the final data after eliminating the invalid data, and the invalid part are the data of the students who fail to participate in the pre-test. By using SPSS17.0, before the experiment, use independent sample $t$ to test the height of the experimental group and the control group, and place the height and height distance data. The confidence interval was $96 \%$. The data results and correlation analysis are shown in Table 2:

Table 2.Relevant test data 


\begin{tabular}{|c|c|c|c|}
\hline & Height $(\mathrm{cm}) \mathrm{x} \pm \mathrm{s}$ & $\begin{array}{c}\text { Run up to touch height }(\mathrm{m}) \\
\mathrm{X} \pm \mathrm{s}\end{array}$ & Shot put(m) $\pm \mathrm{s}$ \\
\hline control group & & & $12.56 \pm 2.79$ \\
$(\mathrm{n}=30)$ & $181.46 \pm 6.28$ & $3.15 \pm 0.13$ & $13.71 \pm 2.73$ \\
\hline study group & & & \\
$(\mathrm{n}=30)$ & $178.25 \pm 5.11$ & $3.17 \pm 0.57$ & -0.857 \\
\hline $\mathrm{T}$ & 0.538 & -0.282 & 0.549 \\
\hline $\mathrm{P}$ & 0.530 & 0.783 & \\
\hline
\end{tabular}

Note: there is significant difference when $\mathrm{p}<0.05$, but there is no significant difference when $\mathrm{p}>0.05$.

\subsection{Experiment Related Organization Process}

The experimental intervention is mainly reflected in the "Internet plus" volleyball teaching method, which is mainly used for volleyball teaching. The main part of the teaching method is self-study on the volleyball learning website before class. The experimental group is to learn the volleyball webpage before class and receive the task list. In this paper, we first determine the test indicators before the experiment, select the participants, through preliminary understanding, exclude the group of irrelevant variables that will affect the experiment (there are many people who have the basis of learning volleyball), and finally determine two groups. The specific physical fitness and vaccination level of the individuals before the experiment were tested, and they were randomly divided into an experimental group and a control group. The statistical analysis of the test results showed that there was no significant difference between two groups. The teaching method of "Internet plus" volleyball technology is adopted, while the control team adopts the traditional teaching method. At the end of the experiment, the experimental indexes were tested. After eight weeks of experiment, the volleyball skill indexes and volleyball theoretical knowledge indexes were tested in the experimental group and the control group. Finally, the results of the pre test and the post test data are compared and analyzed, and the shortcomings and advantages of the "Internet plus" volleyball technology teaching mode applied in smash skills are found. The difference between the traditional teaching mode and the "Internet plus" volleyball teaching mode is compared. The flow chart is shown in Figure 2:

\section{Innovation Analysis of the Internet Plus Volleyball Teaching System in the Context of the}

\section{Information Age}

\subsection{Analysis of Students' Basic Situation}

As the main role of the "Internet plus" volleyball teaching system, students' basic situation will have a direct impact on the teaching effect of "Internet plus" volleyball. Therefore, the "Internet plus" volleyball teaching mode needs to be designed effectively based on the students' basic conditions. The first thing we need to understand is the student's interest in learning, and the strong interest in learning is the motivation to promote students' active learning.

Students' interest in learning will directly affect their learning initiative and enthusiasm. Therefore, the author conducted relevant interviews and surveys on the students. Among them, there are some differences in interest in the "Internet plus" volleyball teaching system between male and female students, as shown in Figure 3: 
Through the investigation of students, the students' preferences for different teaching methods are obtained, as shown in Figure 4. It can be concluded from the figure that the students' favorite teaching method is multimedia courseware, followed by dynamic video teaching and text teaching. A little number of students like audio teaching or other teaching methods. Course wares and textbooks are generally the most direct learning materials for students in the classroom. Multimedia can not only insert the appropriate image, audio and text materials, but also present the teaching content with pictures and texts. As the basic learning materials of students, textbooks, namely text resources, have the characteristics of complete system and strict logic, which is an important way for students to acquire curriculum knowledge. Compared with other resources, text resources can make students calm down, read carefully and deeply understand the content of knowledge between lines. Video teaching combines text, audio and video information to present dynamic and rich course content, mobilize students' multiple consciousnesses, improve teaching effects, and attract students' many interests and hobbies.Therefore, the presentation of the "Internet plus" volleyball teaching system should pay attention to the multimedia courseware, dynamic video teaching and the close connection between textbooks, make full use of multimedia courseware, enhance the effectiveness of volleyball teaching, reasonably present video resources, achieve high efficiency in teaching, and break through the traditional volleyball teaching mode in universities.

4.3 Application of "Internet Plus" Volleyball Teaching in the field of Network Information Age in Colleges

\section{( 1 ) Application of multimedia in college volleyball teaching}

The development of multimedia technology and the development of the internet are interrelated. As the background of the internet age, the new type of technology incorporates text, sound, animation and visual effects and other related functions. In fact, multimedia teaching has existed since ancient times. .Teachers teach with the help of text, sound and pictures. However, in the 1980s, the use of a variety of electronic media, such as slide, projection, recording, video and other comprehensive use and classroom teaching, this teaching technology is also known as multimedia combination teaching or audio-visual teaching. Since the 1990s, with the rapid development and spread of information technology, the multimedia computer has gradually replaced the total use of various teaching aids in the past.Therefore, what we usually call multimedia teaching is a teaching process that uses multimedia computers and pre-built multimedia teaching software, which can also be called computer-assisted education. The multimedia computer completely edits and controls symbols, language, text, sound, graphics, images, images and other media information. According to teaching requirements, it organically combines and presents the various elements of multimedia through a screen or projector. At the same time, According to needs, with the cooperation of sound, through the interactive operation between human and computer, the teaching or training process of user and computer can be completed. It uses computer technology, network technology, communication technology and scientific and standardized management to integrate, integrate and digitize all information resources related to learning, teaching, scientific research, management and life services, so as to form a unified user management, unified resource management and unified authority control. Emphasizes that students can access the university network and the Internet via WiFi at any time to access learning resources conveniently. Teachers can use wireless network to monitor the learning situation of students, to complete the preparation of lessons and conduct scientific research work anytime, anywhere. Its core lies in the application of paperless teaching and the expansion of the wireless network at the 
university.Through the comprehensive operation to complete high school volleyball class, The application of this technical form in volleyball teaching in colleges and universities can promote the processing of educational information and present teaching multidimensional, integration and interaction, specialization, etc. after the fusion of various characteristics, the presentation rate of teaching information can be comprehensively improved. As far as volleyball teaching in schools and universities is concerned, volleyball technology is almost of great significance to volleyball teaching, and the technical difficulty is high and the tactical changes are very complex. If the college physical education teachers simply explain the theoretical knowledge of volleyball, the students' understanding of the intrinsic value of volleyball may have deviation. Only by combining theoretical knowledge with demonstration practice can we realize the requirements of volleyball teaching in schools and universities. For example, the change of tactics and the sense of position in volleyball can't be described only by theory, but must be combined with volleyball sport and practice. The emergence of multimedia technology can be combined with a variety of audio-visual forms to achieve audio-visual teaching effect, which is intuitive and understandable. Students can deepen their understanding of volleyball by watching volleyball technology, sports training, sports competition and routine training and other related resources. And then achieve the goal of college volleyball teaching. For example, teachers collect information and network teaching resources from relevant professional websites before class, and use multimedia to familiarize students with volleyball skills and essentials on the way to class. SPSS17.0 was used for paired sample $t$ test before and after the application of multimedia teaching, and the confidence interval was $96 \%$. The change data of students' volleyball technical test results before and after the application of multimedia teaching are shown in Table 3:

Table 3.Students' Volleyball test results before and after the application of multimedia teaching

\begin{tabular}{|c|c|c|c|c|c|}
\hline Item & Group & $\begin{array}{c}\text { Before the } \\
\text { experiment }\end{array}$ & $\begin{array}{c}\text { After the } \\
\text { experiment }\end{array}$ & $\mathrm{T}$ & $\mathrm{P}$ \\
\hline Skill 1 & $\begin{array}{c}\text { control } \\
\text { group }\end{array}$ & $3.15 \pm 0.18$ & $3.14 \pm 0.14$ & -14.253 & 0.000 \\
\hline Skill1 & study group & $2.85 \pm 0.29$ & $3.16 \pm 0.69$ & -16.326 & 0.000 \\
\hline Skill2 & $\begin{array}{c}\text { control } \\
\text { group }\end{array}$ & $1.57 \pm 0.34$ & $3.15 \pm 0.18$ & -15.751 & 0.000 \\
\hline Skill2 & study group & $1.74 \pm 0.49$ & $3.15 \pm 0.18$ & -9.256 & 0.000 \\
\hline $\begin{array}{c}\text { Up to } \\
\text { standard }\end{array}$ & $\begin{array}{c}\text { control } \\
\text { group }\end{array}$ & $1.68 \pm 2.03$ & $3.15 \pm 0.18$ & -6.215 & 0.000 \\
\hline $\begin{array}{c}\text { Up to } \\
\text { standard }\end{array}$ & study group & $1.81 \pm 2.49$ & $3.15 \pm 0.18$ & -2.697 & 0.005 \\
\hline
\end{tabular}

In order to see the results more intuitively and analyze them, the table is drawn into a column chart, as shown in Figure 5:

\section{( 2 ) Application of information technology in school volleyball venues}

Training place is the basis of volleyball teaching development in colleges and universities. With the continuous deepening and development of intelligence technology, volleyball facilities are gradually developing in the direction of informatization and intelligence, such as the construction of automatic control system, automatic office system, intelligent system, network system, access control system and competition information system. But in the construction of college volleyball venues, its main goal is to promote teaching. Using appropriate information technology to equip venues with 
intelligent system will further improve the problems that may exist in the mutual adaptation of sports venues and modern education. For example, a video recording device is installed in the gymnasium to record the teaching process from various angles. The process of physical education teaching is different from the teaching content of other courses. We can only sum up the experience in practice and find the shortcomings of volleyball. The video recorded by the video monitor can be transmitted to the campus website by teachers, and students can look at it. On the one hand, this method can stimulate the enthusiasm of primary school students to take part in volleyball, so that they can devote themselves to volleyball; on the other hand, it can also provide information for teachers, so that teachers can find out the shortcomings of teaching in students' volleyball, and help teachers constantly improve their teaching methods.

\section{( 3 ) Development of volleyball learning website in colleges and universities}

It is a window and platform for the construction of volleyball education in colleges and universities to develop a special college volleyball learning website. Its content should cover all aspects of college volleyball teaching, forming a diversified, three-dimensional, multi-functional network system. This system can include: the design and implementation of volleyball teaching information module, the design and implementation of volleyball teaching plan, summary and feedback teaching evaluation, volleyball related equipment management, monitoring and improvement of physical fitness monitoring system, diagnosis and rehabilitation of primary school students' sports injury. Information units related to volleyball education, such as scientific selection, technical analysis, scientific training, etc. Organization and management units of off campus activities and volleyball competitions, such as organizing and implementing mass volleyball activities and competitive volleyball activities, and arranging foreign exchange and volleyball cooperation.

( 4 ) Development of "Internet plus" volleyball teaching exclusive APP

In recent years, sports exercise APP is favored by people who like to do exercise. The APP for this kind of exercise often has a high download volume, as shown in Figure 6:

Colleges and universities can imitate such APP organization technicians to develop a software specially designed for volleyball teaching, conform to the trend of some times, and truly achieve "Internet plus Volleyball".

\section{Conclusions}

With the rapid development of computer intelligence technology and the continuous expansion of network coverage, it promotes the rapid development of all steps of life. Contemporary senior students are in the era of digital economic knowledge, and the society has a growing demand for high-quality talents. "Internet plus" teaching breaks in the traditional teaching mode. It takes the convenience of resources, the richness, openness, advanced and sharing of teaching resources, and the advanced nature of teaching ideas change the relationship between teaching methods, teaching methods and teachers and students. The renewal of teaching technology in the era of education will bring about the reform of teaching concepts, and then the teaching form and teaching mode will also enter change. Physical education is a branch of the education industry, which is also of great significance to the development of education. From the current perspective, the physical education teaching mode in China basically stays in the traditional teaching mode, and in the context of the "Internet plus" strategy, it is in line with the emergence of "Internet plus" big data and mobile intelligent terminals. The reform of the physical education teaching mode has become the general trend of the development of physical education teaching. Volleyball course, as the main course of college physical education major curriculum system 
and the primary choice course of cultural students' physical education elective course, occupies an important position in college physical education and plays an important role in volleyball talent training.

This paper selects the innovation of the Internet plus volleyball teaching system under the background of the internet information age to study. The SPSS17.0 can calculate the confidence interval of 0.96 . The way of using multimedia in the "Internet plus" volleyball teaching system can improve the volleyball performance of students. In the context of "Internet plus", "Internet plus" volleyball teaching mode has been built, and volleyball technology learning platform are established by multimedia information technology, network volleyball learning resources and computer aided tools is operable and effective. "Internet plus" volleyball technology teaching mode applied in volleyball teaching can actively arouse students' enthusiasm and interest in classroom learning, and improve students' ability of explaining and demonstrating and autonomous learning.

By studying "Internet plus"of internet application in volleyball teaching system and establishing volleyball timetable model in colleges and universities, we can conclude that "Internet plus" can be applied in the teaching process, volleyball teaching and training venues in universities, volleyball website development and "Internet plus" volleyball APP development.

\section{Abbreviation}

No abbreviations

\section{Competing Interests}

These no potential competing interests in our paper. And all authors have seen the manuscript and approved to submit to your journal. We confirm that the content of the manuscript has not been published or submitted for publication elsewhere.

\section{Declarations}

Ethical Approval and Consent to participate: Approved.

Consent for publication: Approved.

Availability of supporting data: We can provide the data.

\section{Author's Contributions}

All authors take part in the discussion of the work described in this paper.

\section{Fund}

$$
\text { No project support }
$$

\section{References}

[1] Deren LI,Xin SHEN,Nengcheng CHEN,Zhifeng XIAO.Space-based information service in Internet Plus Era.Science China(Information Sciences),2017,60(10):229-238.

[2]Kim I . Exploring changes to a teacher's teaching practices and student learning through a volleyball 
content knowledge workshop. European Physical Education Review, 2016, 22(2):1-18.

[3]Dao S D , Abhary K, Marian R. A Stochastic Production Scheduling Model for VCIM Systems. Intelligent Industrial Systems, 2016, 2(1):85-101.

[4]Zhao Z , Xiong W , Fang J . Impact of Internet plus to China Economy Development. Modern Economy, 2016, 07(9):933-944.

[5]Zhang B , Peng P . Research on the Development of Education Resources for the Internet Plus Universities in the National Health Field. Eurasia Journal of Mathematics ence \& Technology Education, 2017, 13(8):5085-5093.

[6]Liu S M , Kim Y . Special issue on internet plus government: New opportunities to solve public problems?. Government Information Quarterly, 2018, 35(1):88-97.

[7]Yang F , Xie P , Xiang B . How to Promote the New Energy Vehicles under China's "Internet plus" Initiative: A Review. Energy and Power Engineering, 2020, 12(5):154-181.

[8]Ding X . "Internet Plus" urban production. Jisuanji Jicheng Zhizao Xitong/computer Integrated Manufacturing Systems Cims, 2018, 24(2):427-443.

[9]Kim I . Exploring changes to a teacher's teaching practices and student learning through a volleyball content knowledge workshop. European Physical Education Review, 2016, 22(2):1-18.

[10]Zhao C . Application Status and Trend of "Internet Plus" Modern Agriculture in China and Abroad. Strategic Study of Chinese Academy of Engineering, 2018, 20(2):50-56.

[11]Wang L, Huang R , Chen Z, et al. The Application of "Internet Plus Nursing Service" Mode under the Epidemic of Novel Coronavirus Pneumonia. Open Journal of Social ences, 2020, 08(5):255-264.

[12]Antonio García-de-Alcaraz a b, Rodrigo Ramírez-Campillo c, Miguel Rivera-Rodríguez d, et al. Analysis of jump load during a volleyball season in terms of player role. Journal of ence and Medicine in Sport, 2020, 23( 10):973-978.

[13]Khitam M , Ay, Mohammad A, et al. The impact of Teaching Program Based on Mental Training on learning The Performance and Accuracy of The Hook Serve in Volleyball. Dirasat: Administrative Sciences, 2019, 4(44):189-203.

[14]Hadi S R , Marhendinata H . Movement Modeling And Learning Formation Through Youtube Video To Improve Students Volleyball Passing Of SMP Negeri 3 Taman Sidoarjo. JP JOK (Jurnal Pendidikan Jasmani Olahraga dan Kesehatan), 2020, 3(2):177-191.

[15]A C D S P , A R P G , Natália Miwa Yoshida b, et al. Could regular practice of volleyball modulate salivary secretory immunity in children? Cross-sectional and longitudinal studies. Apunts Sports Medicine, 2020, 55( 205):29-37.

[16]Prasanna A . RELATIONSHIP OF PSYCHOLOGICAL VARIABLES IN VOLLEYBALL. High Technology Letters, 2020, 26(6):304-312.

[17]Souza J J D , Grande R S , Bahls R, et al. EVALUATION OF THE ORAL HEALTH CONDITIONS OF VOLLEYBALL ATHLETES. Revista Brasileira de Medicina do Esporte, 2020, 26(3):239-242.

[18]Costa G D C T , Castro H D O , Fabíola de Araújo Cabral, et al. Content Validity of scenes of the Declarative Tactical Knowledge Test in Volleyball - DTKT:Vb. Revista Brasilra de Cineantropometria e Desempenho Humano, 2017, 18(6):629-637.

[19]Alcaraz A G D , Ortega E , José M Palao. Game phases performance in men's volleyball: from initial to top-level categories. RICYDE. Revista internacional de ciencias del deporte, 2020, XVI(61):257-266.

[20]Yang L , Xie C . 116.Research on Model of Course Scheduling System for Ideological and Political 


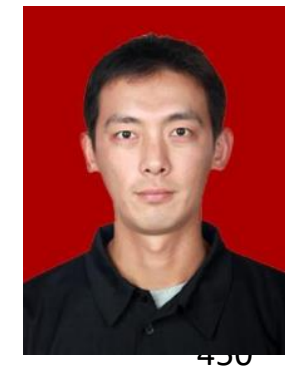

Tian Yang born in Handan, Hebei Province, graduated from Guangzhou Sport University, with a master's degree. He is currently a lecturer in Guangdong Polytechnic of Industry and Commerce, majoring in physical education and training. E-mail: 0001160024@gdgm.edu.cn 
471

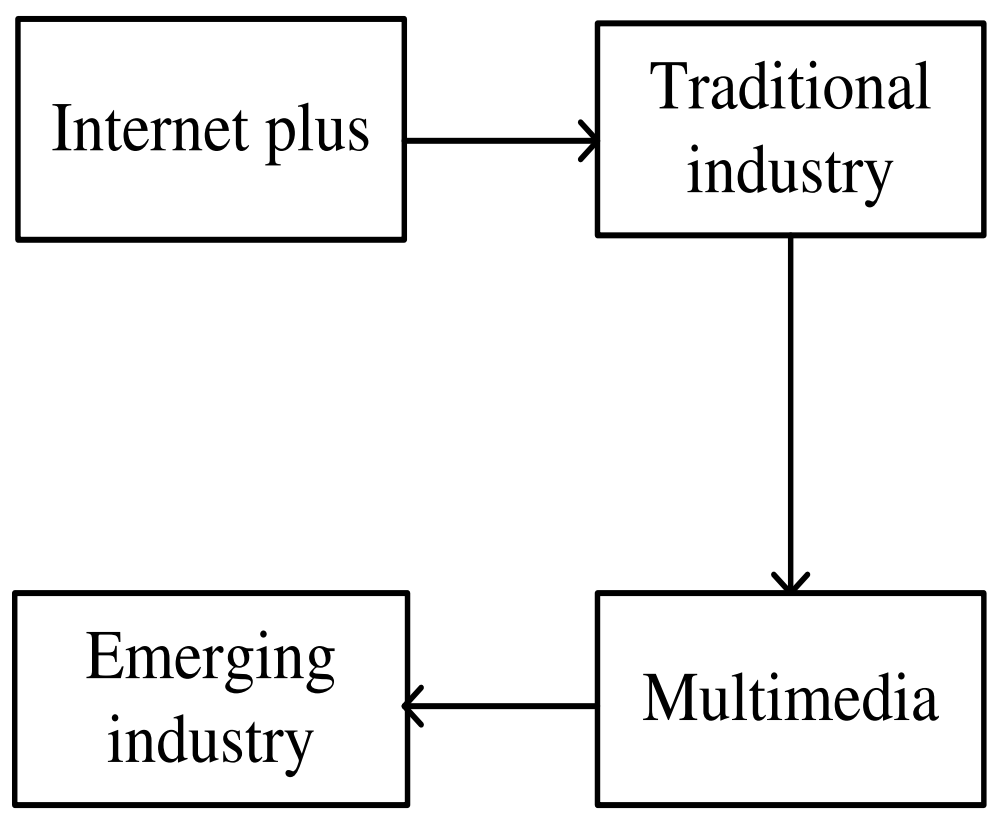

Figure 1.The Internet plus application process

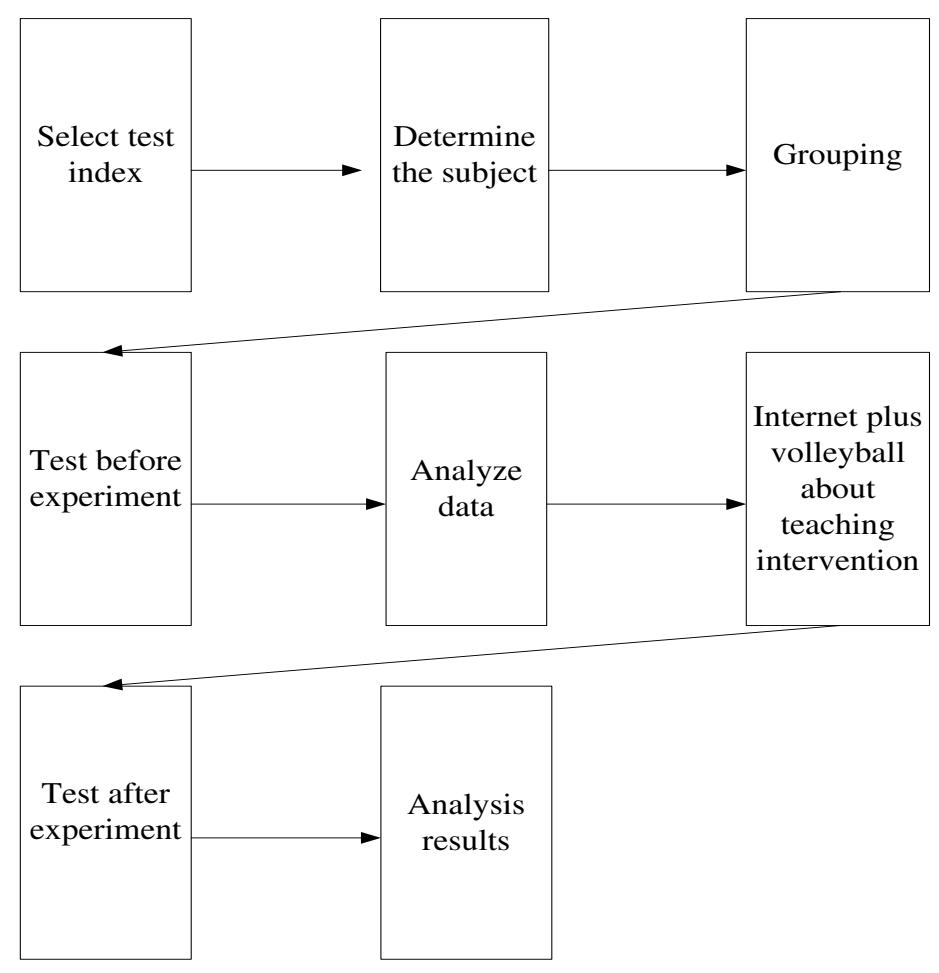

Figure 2.Experimental organization process 


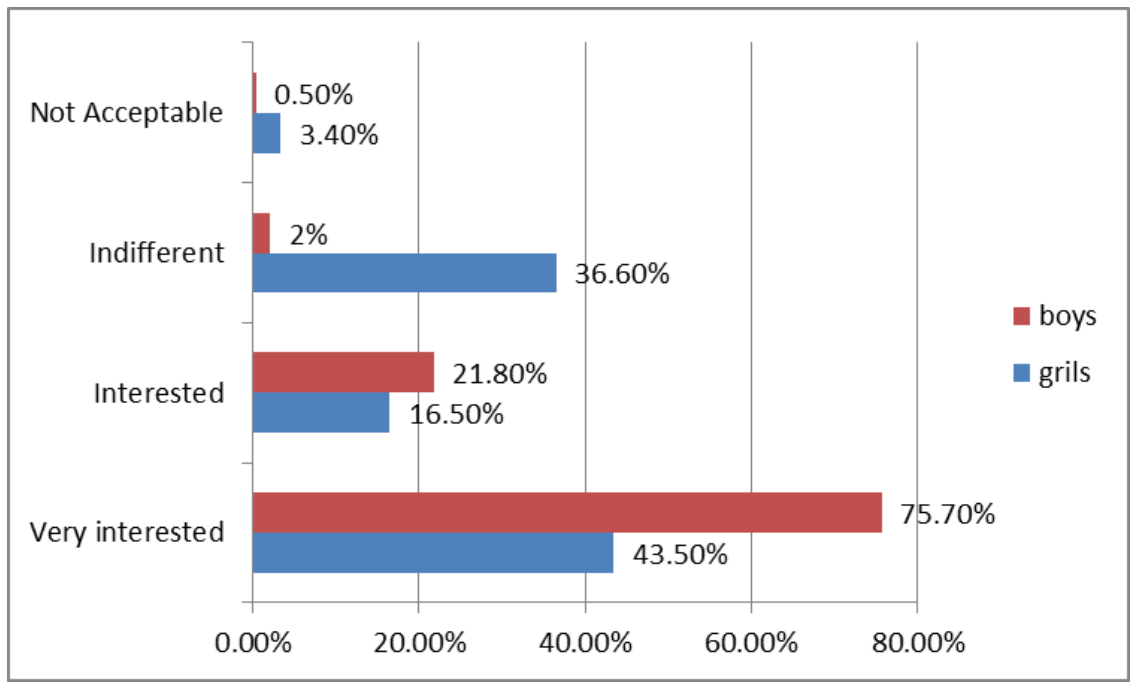

Figure 3.Students' interest

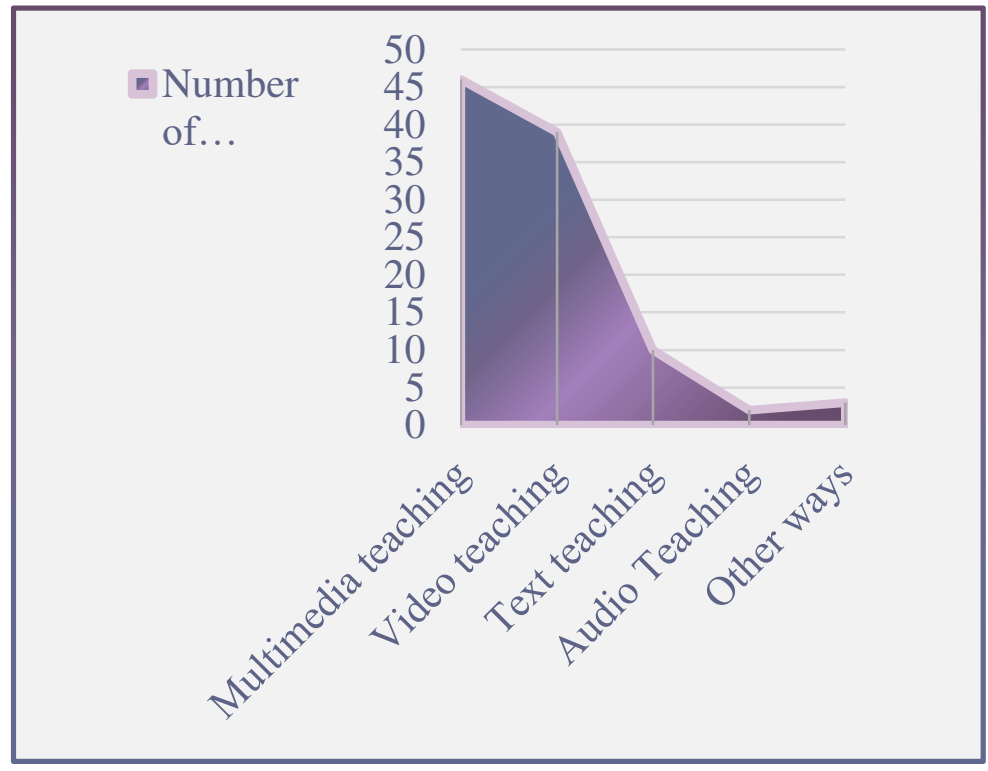

Figure 4.Students' preference for different teaching methods of Teachers 
479

480

481

482

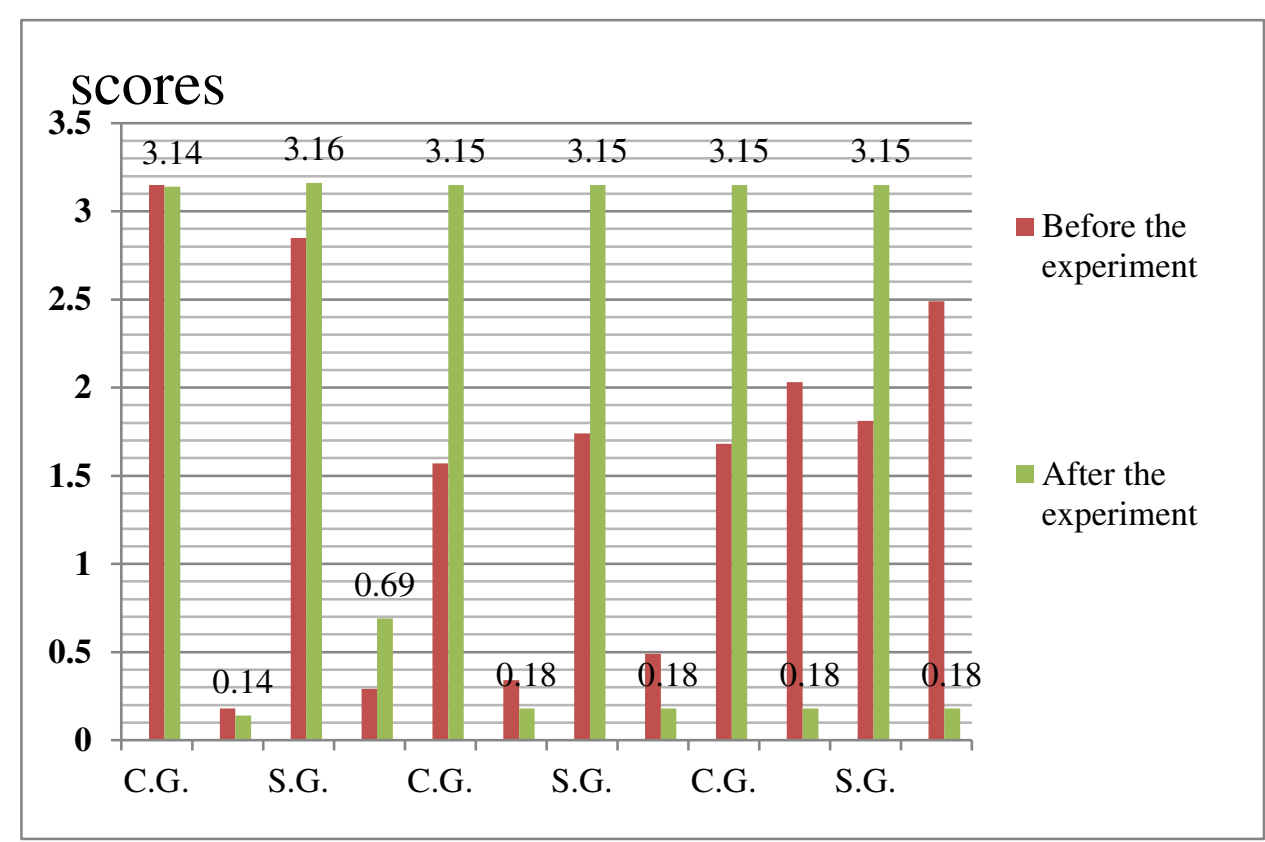

Figure 5.Students' volleyball test results before and after the application of multimedia teaching ( Note:C.G. is control group , S.G. is study group )

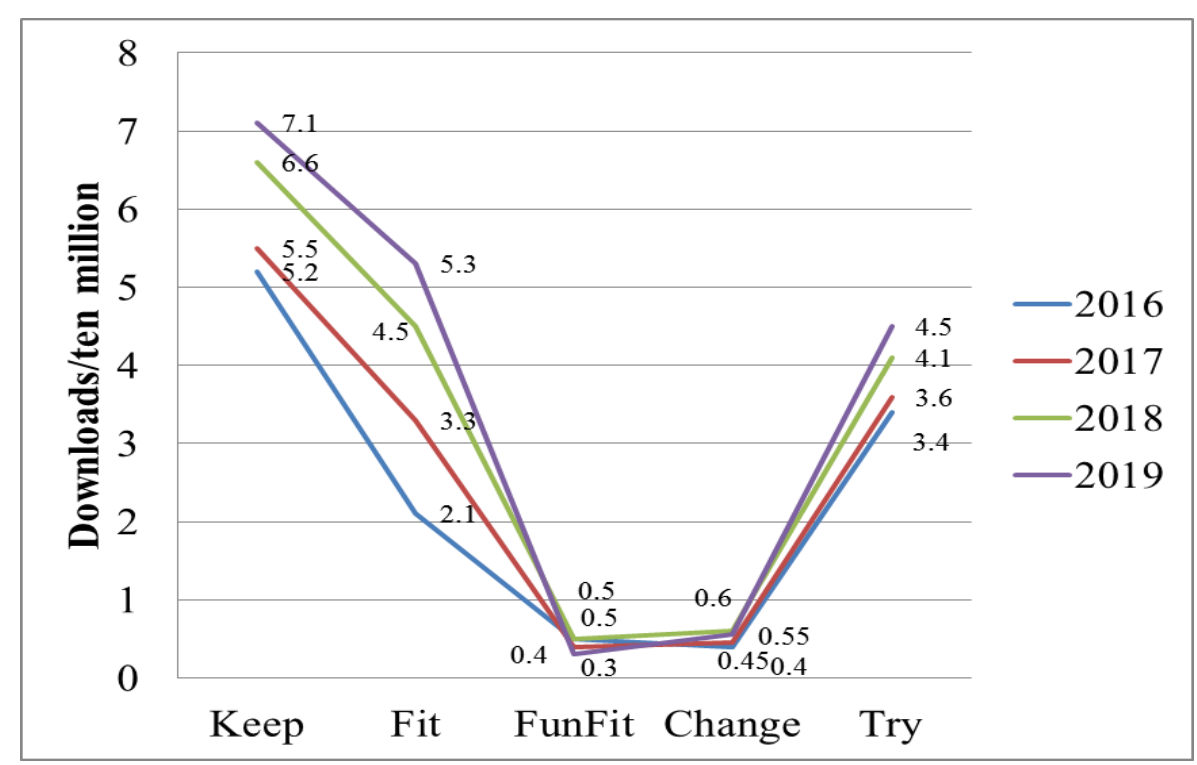

Figure 6.Sports app downloads 
Figures

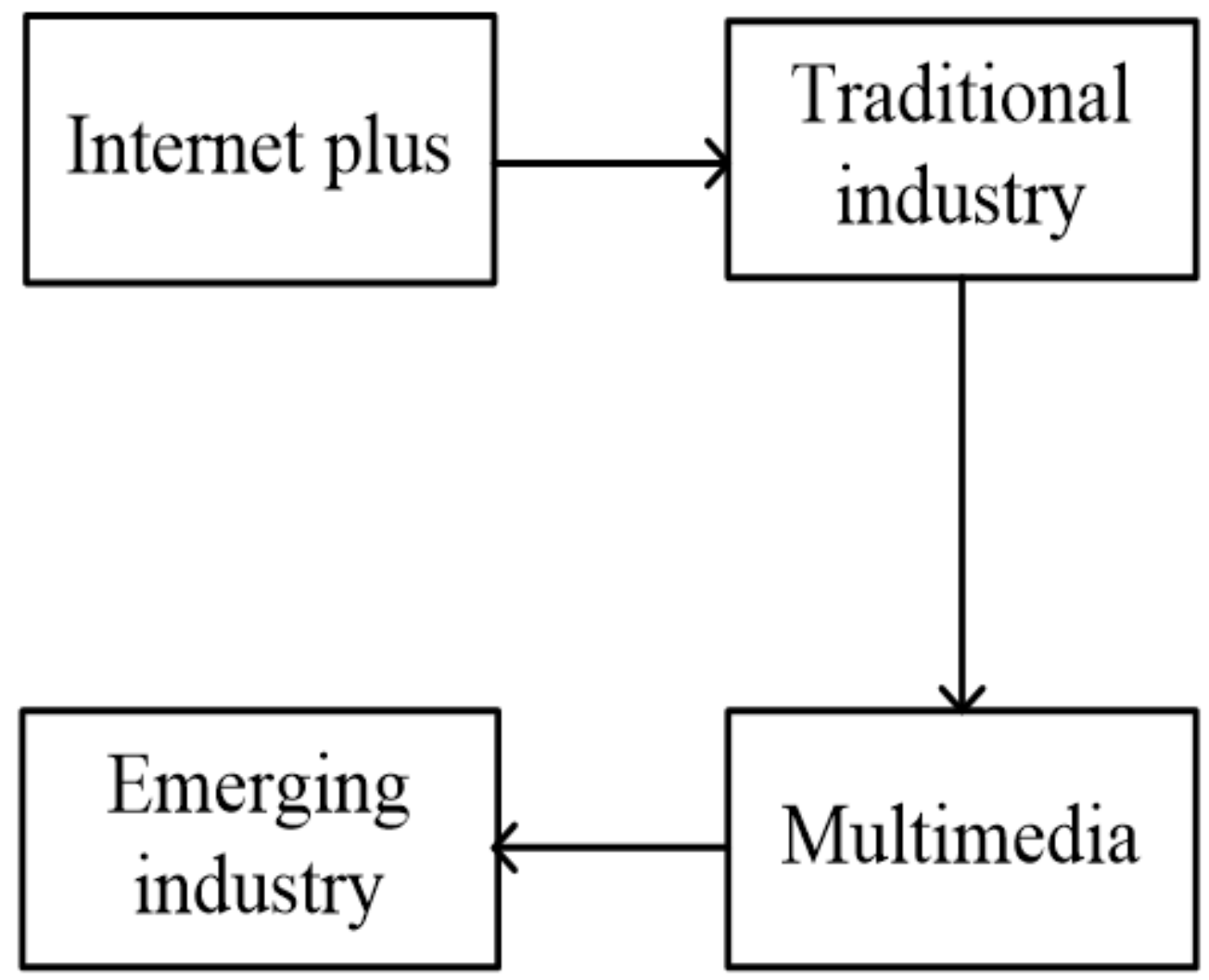

Figure 1

The Internet plus application process 

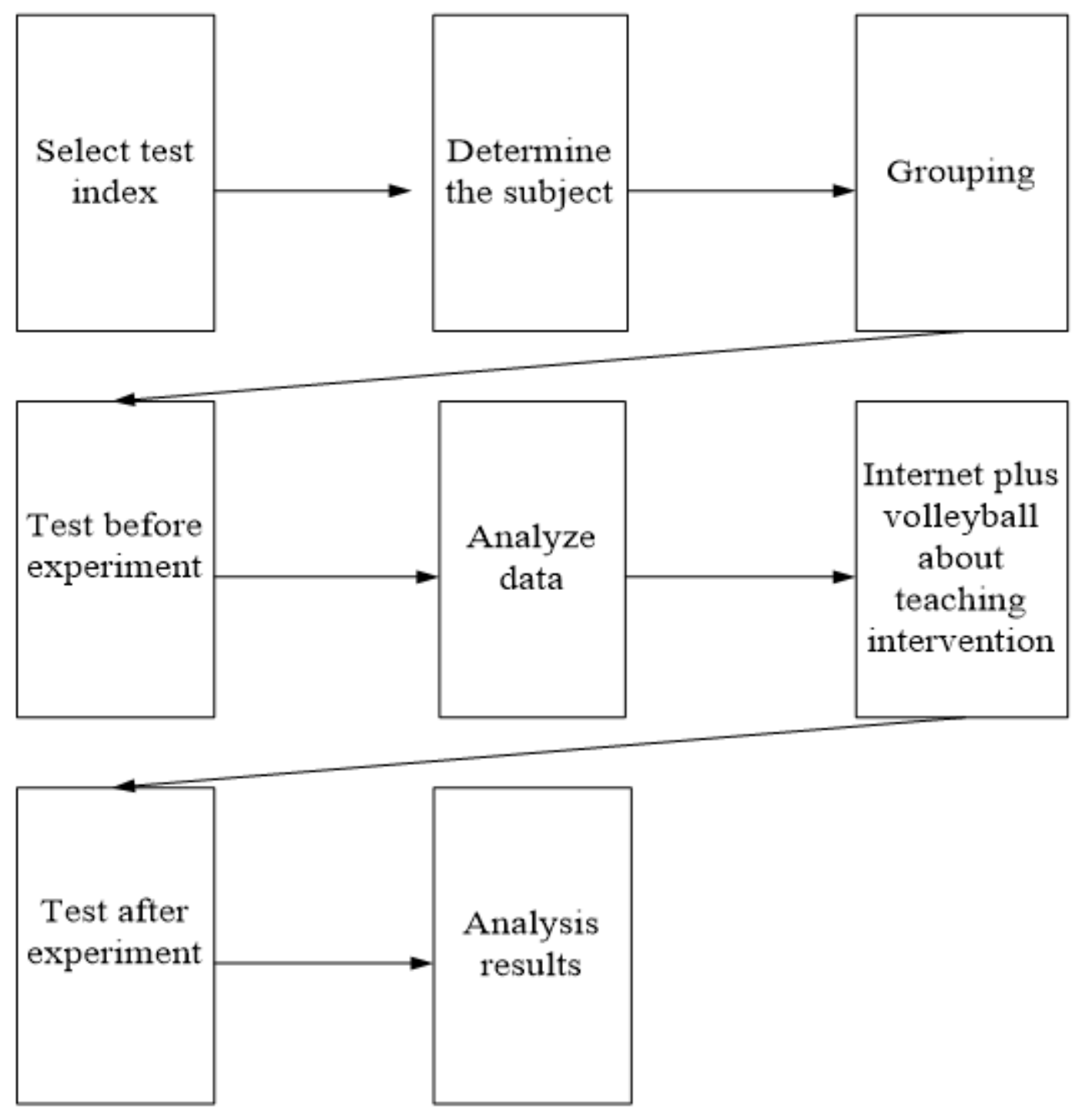

Figure 2

Experimental organization process 


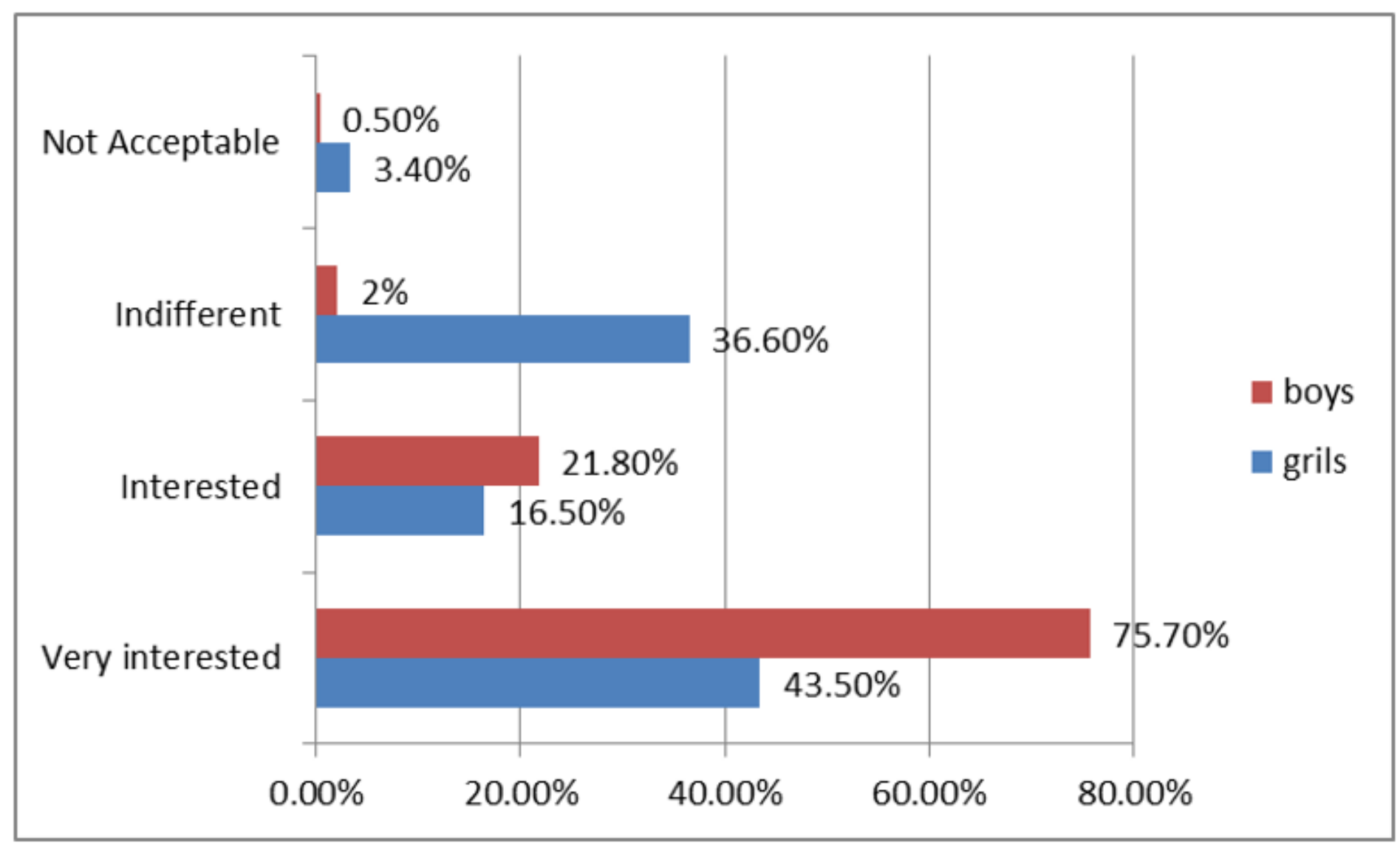

Figure 3

Students' interest 


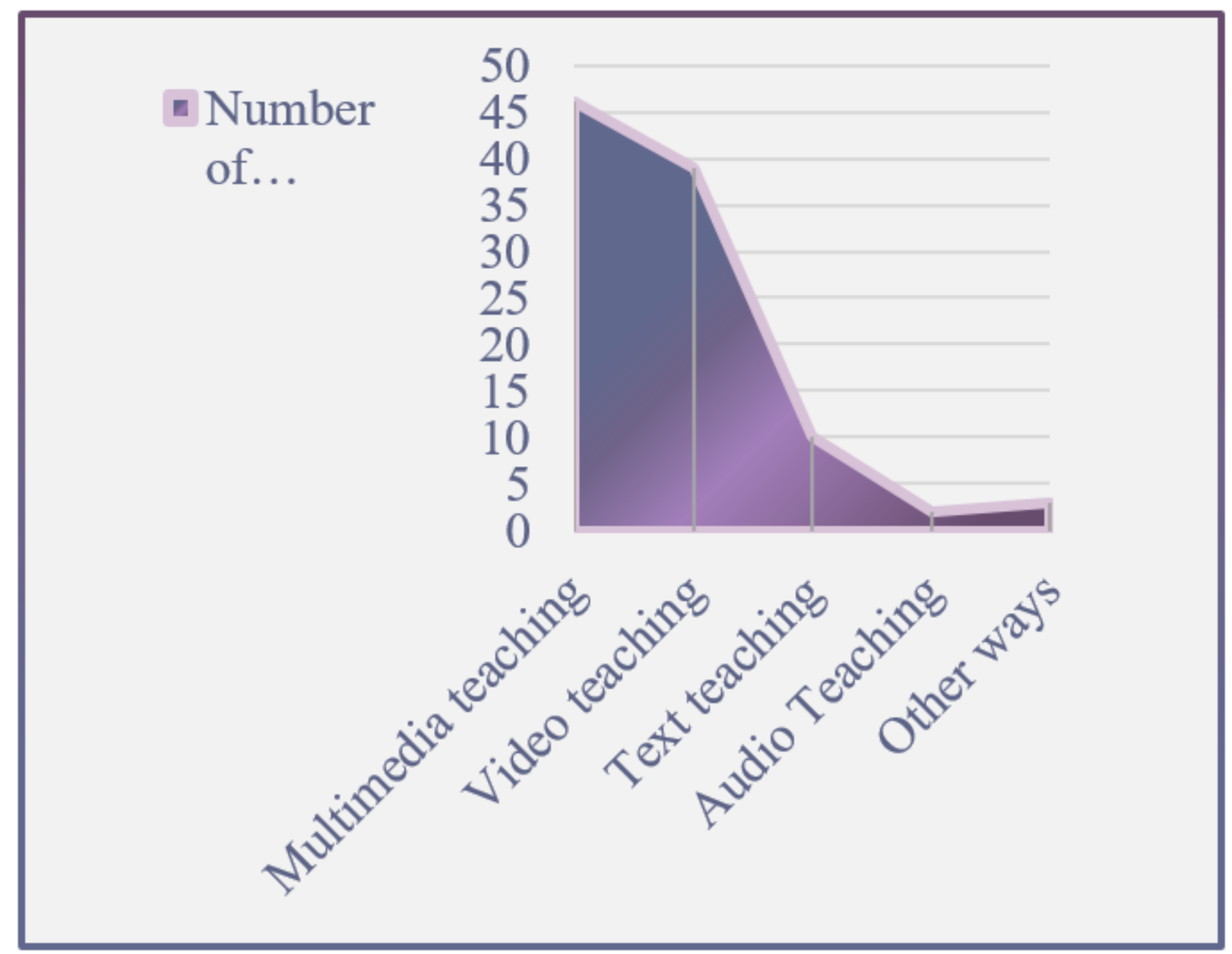

Figure 4

Students' preference for different teaching methods of Teachers 


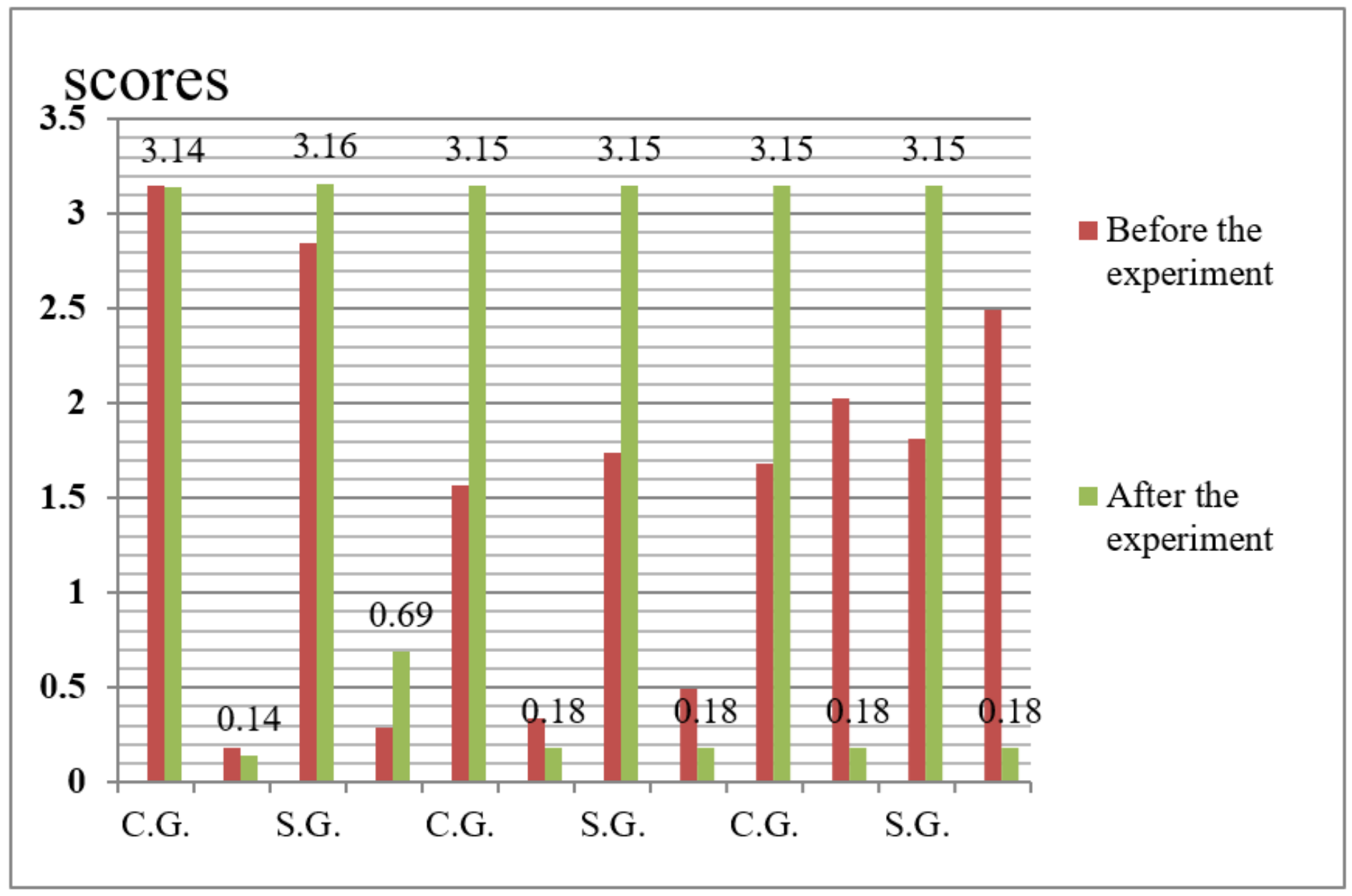

Figure 5

Students' volleyball test results before and after the application of multimedia teaching $₫$ Note:C.G. is

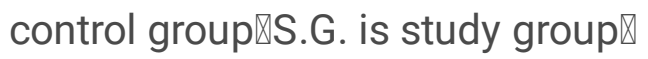




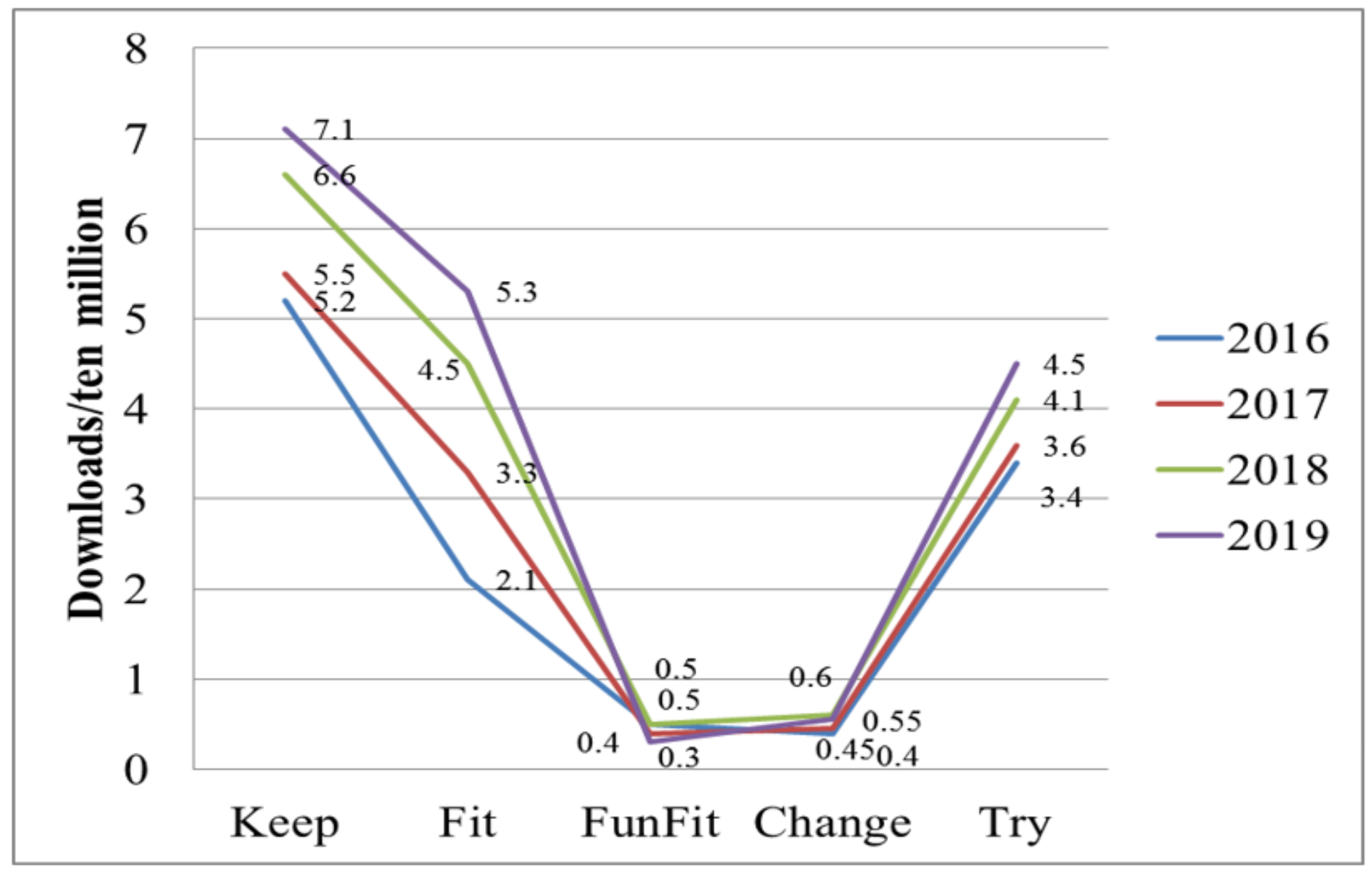

Figure 6

Sports app downloads 